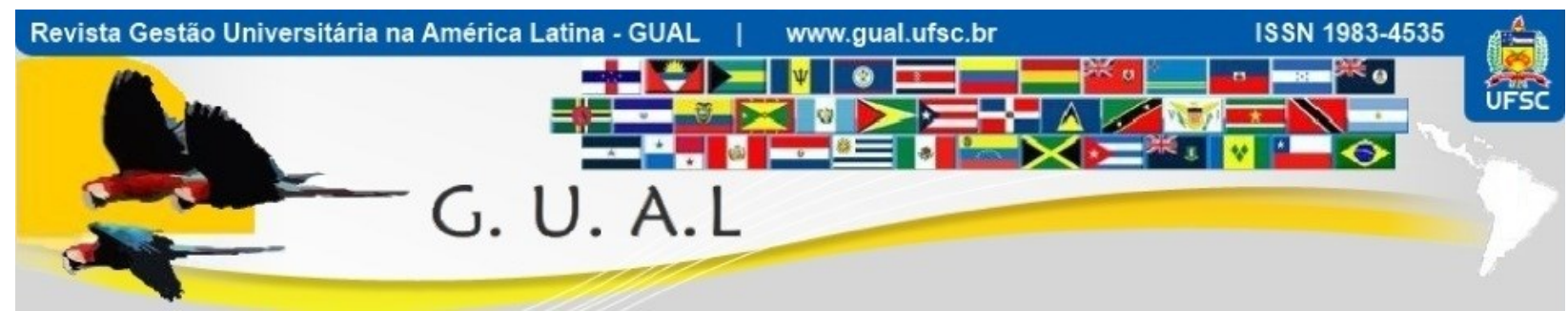

DOI: http://dx.doi.org/10.5007/1983-4535.2020v13n3p98

\title{
PRÁTICAS DE ACCOUNTABILITY: TRANSPARÊNCIA E PRESTAÇÃO DE CONTAS NAS INSTITUIÇÕES PÚBLICAS DE ENSINO SUPERIOR DA REGIÃO SUL DO BRASIL
}

\section{ACCOUNTABILITY PRACTICES: TRANSPARENCY IN THE PUBLIC HIGHER EDUCATION INSTITUTIONS IN SOUTHERN BRAZIL}

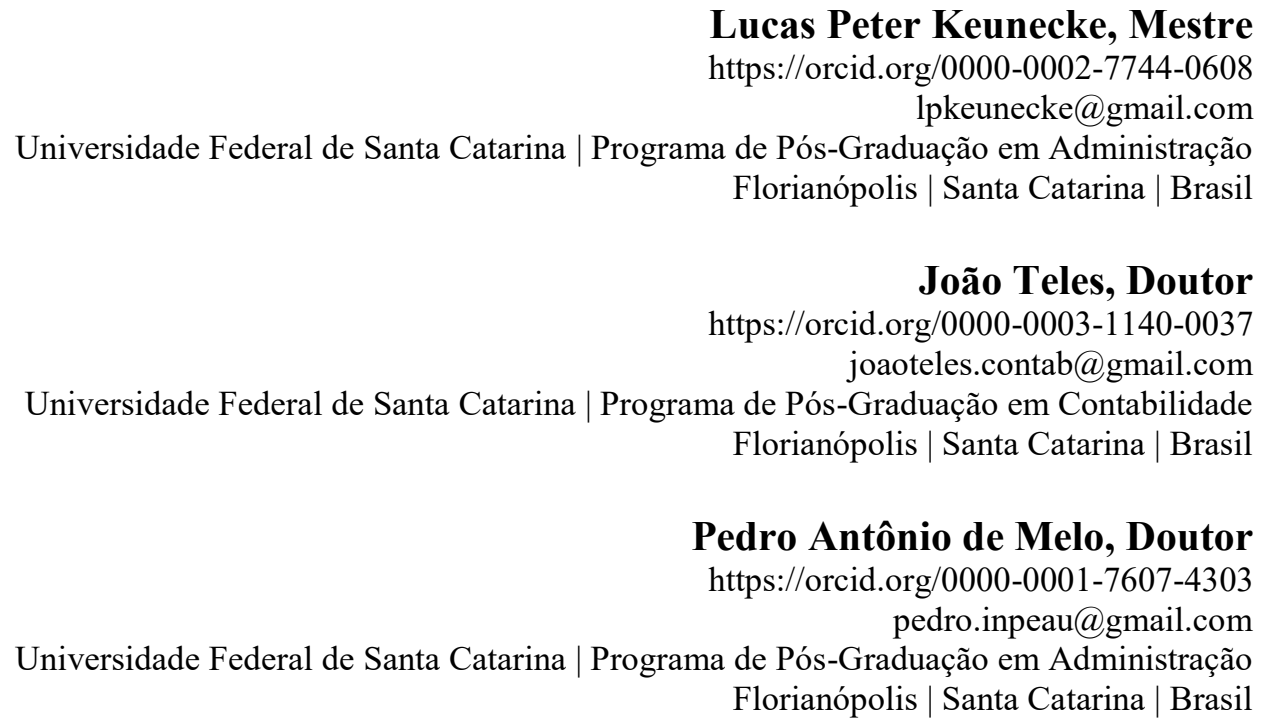

Recebido em 06/dezembro/2019

Aprovado em 27/junho/2020

Publicado em 01/setembro/2020

Sistema de Avaliação: Double Blind Review

Esta obra está sob uma Licença Creative Commons Atribuição-Uso. 


\begin{abstract}
RESUMO
Este artigo analisa a transparência dos portais eletrônicos das instituições públicas de ensino superior da região sul do Brasil, quanto às contas públicas e ações praticadas para aumento da transparência pública. $\mathrm{O}$ universo da pesquisa contemplou vinte e nove instituições, sendo onze universidades federais, nove universidades estaduais, três universidades municipais e seis institutos federais. O panorama da disponibilização das contas públicas permitiu identificar um baixo nível de transparência, especialmente nas universidades municipais. Verificou-se que estas instituições ainda são incapazes de dar pleno atendimento à Lei de Acesso à Informação, a qual trouxe novidades importantes para a transparência pública. $\mathrm{O}$ descumprimento de diversos aspectos legais implica na oferta de um conteúdo desqualificado pela administração, dificultando a construção de um ambiente propício à accountability, o que tolhe de inúmeros usuários interessados a possibilidade concreta de realizarem um controle social mais efetivo.
\end{abstract}

Palavras-chave: Accountability. Transparência. Governo Eletrônico. Instituições de Ensino Superior.

\begin{abstract}
This article analyzes the transparency of the electronic portals of public higher education institutions in southern Brazil, regarding public accounts and actions taken to increase public transparency. The research universe included twenty-nine institutions, eleven federal universities, nine state universities, three municipal universities and six federal institutes. The panorama of the availability of public accounts made it possible to identify a low level of transparency, especially in municipal universities. It was found that these institutions are still unable to fully comply with Acess to Information Act, which has brought important news for public transparency. Failure to comply with various legal aspects implies the offer of content that is disqualified by management, making it difficult to build an environment conducive to accountability, which hinders many interested users the concrete possibility of achieving a more effective social control.
\end{abstract}

Keywords: Accountability. Transparency. Electronic Government. Higher Education Institutions. 


\section{INTRODUÇÃO}

A opacidade que cerca a ação da burocracia configura-se como uma das principais causas dos males e das deficiências da administração pública, sendo um dos pressupostos para o seu mau funcionamento, pois impede que o cidadão tenha acesso às informações e a vigie. Isso traz uma dificuldade adicional em obrigar o Estado a seguir critérios gerais, uniformes e impessoais, garantindo justiça e equidade no tratamento de todos (JARDIM, 1999).

A visibilidade dos atos da administração pública ocupa lugar de destaque sempre que existe discussão sobre os principais problemas que circundam a atuação estatal. Constantemente a transparência é citada como um mecanismo capaz de proporcionar condições para maiores níveis de confiança entre governantes e governados, além de contribuir para a redução da corrupção no espaço público (SACRAMENTO; PINHO, 2007).

Neste cenário, o termo accountability vem ganhando força. Sua ampla utilização na literatura anglo-saxônica e a expansão para a literatura nacional atestam sua importância (Ceneviva, 2006). O termo possui um vínculo estreito com a transparência e ambos englobam muitas das mesmas ações, como, por exemplo, a comunicação e a prestação de contas (International Organization of Supreme Audit Institutions [INTOSAI], 2010).

Desde a publicação da Lei de Acesso à Informação (LAI) em 2011, o ato de prestar contas foi ampliado. Há uma série de informações, sobretudo quanto às receitas e despesas públicas, que devem ser emitidas por órgãos e entidades em suas páginas eletrônicas nas diferentes esferas governamentais. Nesse sentido, os portais das instituições públicas devem permitir que a sociedade obtenha acesso adequado às suas contas.

Em instituições de ensino superior (IES), este processo é ainda mais relevante, pois possuem, em parte considerável dos usuários de seus serviços, pessoas que estão aptas a analisar, compreender e criticar as informações divulgadas. Tais instituições afetam e são afetadas diretamente pela sociedade na qual estão inseridas, por questões que vão desde o subsídio dos cofres públicos e os impostos pagos pelos cidadãos até a contrapartida que deve ser adotada de prestar contas dos recursos ali alocados (LYRIO et al., 2008). No Brasil, a região sul é a região com o maior percentual de pessoas vinculadas ao ensino superior público (Instituto Brasileiro de Geografia e Estatística [IBGE], 2015).

Por conta disto, faz-se pertinente saber: em qual medida as páginas eletrônicas das instituições públicas de ensino superior do sul do Brasil são transparentes em relação às contas públicas? Assim, este trabalho se propõe a analisar a transparência dos portais 
eletrônicos das IES públicas do sul do Brasil quanto às contas públicas e ações praticadas para aumento da transparência pública, proporcionando um ranking de transparência das IES analisadas, nos parâmetros: conteúdo, série histórica/frequência de atualização e usabilidade.

Este trabalho ocupa uma lacuna no que diz respeito à análise conjunta de diferentes enquadramentos de IES (universidades e institutos federais) em diferentes esferas de governo (federal, estadual e municipal). Dada a necessidade de aperfeiçoamento dos mecanismos de participação, possibilitando ao cidadão agir enquanto agente de fiscalização, se constitui a justificativa social para a pesquisa. Se por um lado o caminhar legislativo brasileiro tem se manifestado, no intuito de posicionar a Administração Pública ao alcance da sociedade, por outro lado a análise da transparência pode apontar falhas que dificultam o controle social.

\section{REVISÃO TEÓRICA}

\subsection{ACCOUNTABILITY}

Accountability confunde-se com a responsabilidade que alguém assume perante outrem, sujeitando-se a obrigações em caso de descumprimento (Campos, 1990). O sentido de accountability amplamente aceito é o que se relaciona com o processo de prestar contas a alguém. Esta noção encontra-se vinculada ao núcleo principal do termo e é a percepção que há mais tempo vem sendo utilizada por pesquisadores (MULGAN, 2000). Na sua essência, o termo está relacionado aos detentores do poder e a forma com que as regras limitam este poder (SCHEDLER, 1999). A accountability surge como uma forma de impedir que o escolhido dentre os membros de um grupo para determinada ação viole o interesse daquele mesmo grupo. É a capacidade de se exigir que os representantes expliquem o que fazem, respondam por seus atos e sejam punidos ou mesmo recompensados (ARATO, 2002). Pode-se dizer que o termo diz respeito à capacidade que possuem os cidadãos em impor sanções aos governantes, retirando do cargo aqueles que possuem desempenho insatisfatório e reconduzindo ao cargo aqueles que desempenham bem sua missão. Abarca também a prestação de contas daqueles que detêm mandato e o veredito popular sobre estas contas (MIGUEL, 2005).

Adotando a teoria do principal-agente, a accountability pode ser compreendida como um mecanismo onde ocorre a responsabilização do político (agente) por parte daqueles que o elegem (principal), por meio de um instrumento de sanção (voto) que irá incentivar ou desestimular os representantes a seguirem o interesse do grupo (PRADO, 2008). 


\section{PRÁTICAS DE ACCOUNTABILITY: TRANSPARÊNCIA E PRESTAÇÃO DE CONTAS NAS INSTITUIÇÕES PÚBLICAS DE ENSINO SUPERIOR DA REGIÃO SUL DO BRASIL \\ DOI: http://dx.doi.org/10.5007/1983-4535.2020v13n3p98}

De acordo com a Teoria da Agência, quando aquele que detém o poder (principal) passa este poder a alguém para administrá-lo (agente), o poder de decisão sobre o novo proprietário padece de um conflito de interesse, já que tanto agente como principal têm por objetivo a maximização de sua utilidade (BHATTA, 2003). A accountability serve como um mecanismo que visa alinhar estes interesses. Visto que atua como um freio sobre o poder recebido pelos mandatários do poder público, o termo pode ser analisado como um parâmetro da qualidade democrática (MARIA, 2010).

Portanto, o tema pode ser compreendido como um processo que envolve a prestação de contas e, eventualmente, a responsabilização dos governantes em razão do poder que a eles é delegado e, como consequência, torna-se um fator determinante para a consolidação da democracia (MIGUEL, 2005).

\subsection{LEGISLAÇÃO INDUTORA DA TRANSPARÊNCIA E DA PRESTAÇÃO DE CONTAS}

A transparência distingue-se da publicidade, pois exige para sua ocorrência, além da oferta ao público dos números e atos de gestão, a disponibilização de informações em condição de serem interpretadas pela população em geral (CRUZ, 2012). Já a transparência das contas públicas é composta também pelos elementos compreensibilidade e utilidade para decisões. A compreensibilidade está relacionada à forma com que as informações são apresentadas, com uma linguagem acessível, adequada ao perfil do usuário. Já a utilidade está fundamentada na relevância das informações, as quais devem ser confiáveis e verídicas com padrões que permitam a comparabilidade entre períodos e entidades (PLATT NETTO, 2007).

Atualmente, o caminhar legislativo no Brasil aponta para a publicação de uma série de normas voltadas ao aumento da disponibilização das informações aos cidadãos. Quanto à prestação de contas, a Constituição Federal (1988) a prevê como obrigação de todos aqueles que arrecadem, administrem ou gerenciem dinheiros, valores e bens públicos, na forma da lei, sob pena de responsabilidade, conforme disposto em seu artigo $5^{\circ}$, inciso XXXIII e artigo 70. Após um lapso temporal de mais de uma década da promulgação da Constituição Federal, como resposta às demandas da sociedade, o Estado passa a disponibilizar instrumentos regulatórios que disciplinam o acesso à informação (GAMA; RODRIGUES, 2016).

Recursos recentemente disponibilizados como os portais da transparência e as seções de transparência, as quais devem contemplar os orçamentos, planos, prestação de contas, pareceres de contas, entre outros, foram inseridos no cenário do governo eletrônico por meio 
da Lei de Responsabilidade Fiscal (LRF) - Lei Complementar $n^{0} 101$ (2000), Lei da Transparência - Lei Complementar no 131 (2009), Decreto $n^{\circ} 7.185$ (2010) e LAI - Lei $n^{\circ}$ 12.527 (2011). A LRF (2000) reforçou a exigência de transparência, possuindo em sua estrutura capítulo que dispõe sobre a Transparência, Controle e Fiscalização e sobre a Transparência da Gestão Fiscal. A elaboração da lei fundamentou-se no binômio transparência e responsabilidade (SANTOS, 2004) e desde então é considerada o principal instrumento regulador das contas públicas no Brasil, determinando metas, limites e condições para gestão das receitas e despesas (LEITE FILHO; COLARES; ANDRADE, 2014).

Dispondo sobre a Transparência, o Controle e a Fiscalização, o Capítulo IX da LRF (2000) teve sua aplicação ampliada pela Lei Complementar $n^{\circ} 131$ (2009), também conhecida como Lei da Transparência, a qual estabelece normas de finanças públicas voltadas para a responsabilidade na gestão fiscal, a fim de determinar a disponibilização, em tempo real, de informações pormenorizadas sobre a execução orçamentária e financeira da União, dos Estados, do Distrito Federal e dos Municípios. Destaca-se também a possibilidade introduzida pelo Art. 73-A da Lei da Transparência (2009), o qual dispõe que qualquer cidadão pode denunciar ao respectivo Tribunal de Contas e ao órgão competente do Ministério Público o descumprimento das prescrições estabelecidas na LRF, como as relativas à publicação de informações, fomentando com isto o amadurecimento da accountability societal e a ocorrência da accountability horizontal.

O Decreto $\mathrm{n}^{\mathrm{o}} 7.185$ (2010), que também alterou o texto original da LRF (2000), regulamenta o padrão mínimo de qualidade do sistema integrado de administração financeira e controle, sobretudo quanto à disponibilização das informações, em meio eletrônico, pela internet, sem exigências de cadastramento de usuários ou utilização de senhas para o acesso que possibilitem amplo acesso público até o primeiro dia útil subsequente à data do registro contábil no respectivo sistema.

Já a Lei no 12.527 - LAI (2011) figura como marco na implantação de uma política de acesso às informações públicas e do governo aberto e tem a finalidade de garantir o acesso à informação mediante procedimentos objetivos e ágeis, transparentes e que em sua composição possuam linguagem de fácil compreensão. A LAI prevê duas modalidades de transparência: a ativa e a passiva. A primeira se caracteriza pela divulgação espontânea das informações pelo poder público e a segunda se caracteriza pelo acesso à informação por meio de demandas dos cidadãos ao Estado. 


\section{PRÁTICAS DE ACCOUNTABILITY: TRANSPARÊNCIA E PRESTAÇÃO DE CONTAS NAS INSTITUIÇÕES PÚBLICAS DE ENSINO SUPERIOR DA REGIÃO SUL DO BRASIL \\ DOI: http://dx.doi.org/10.5007/1983-4535.2020v13n3p98}

Por suas características, Andrade (2014) dispõe que a LAI pode ser considerada um mecanismo de accountability. A norma pode ser analisada nas duas dimensões propostas por Schedler (1999): ansewability e enforceability. A primeira, de caráter informacional, relaciona-se as formas de transparência ativa e passiva, as quais dão ao cidadão o direito de obter e solicitar informações e também receber justificativas no caso de decisão negativa de acesso. A segunda, de caráter punitivo, relaciona-se a necessidade das organizações e funcionários se adaptarem a nova cultura de divulgação de informações, sob pena de responsabilização.

Neste sentido, a LAI (2011) estabelece que os sítios deverão atender, dentre outros, aos seguintes requisitos: a) conter ferramentas de pesquisa de conteúdo que ofereçam acesso à informação com linguagem de fácil compreensão; b) indicar local e instruções que permitam ao interessado comunicar-se, por via eletrônica ou telefônica; c) manter atualizadas as informações disponíveis para acesso; d) possibilitar a gravação de relatórios em diversos formatos eletrônicos, inclusive abertos e não proprietários, tais como planilhas e texto, de modo a facilitar a análise das informações; e) possibilitar o acesso automatizado por sistemas externos em formatos abertos, estruturados e legíveis por máquina.

Mesmo com um distanciamento entre a prática e o esperado pelo legislador, deve-se ressaltar que as normas de acesso à informação, a exemplo das leis aqui estudadas, são etapas primordiais para a construção de políticas efetivas de transparência. A mera promulgação de leis que tratam deste assunto constitui um avanço da sociedade em busca de um governo mais transparente, com maior accountability e prevalência do interesse público (LOPES, 2011).

\subsection{TRANSPARÊNCIA E GOVERNO ELETRÔNICO EM IES PÚBLICAS}

Platt Neto, Cruz e Vieira (2006) abordaram a transparência das contas públicas na Universidade Federal de Santa Catarina, com foco prático na utilização da internet como mecanismo de publicidade. Dentre os aspectos negativos, a não disponibilização de notas explicativas nos balanços públicos os demonstrativos de execução orçamentária em formato de imagem, dificultam a captura das informações pelos usuários interessados.

Roczanski (2009) analisou as práticas da Universidade Estadual de Santa Catarina sob a ótica da accountability e constatou que embora exista um caminho trilhado pela legislação visando a sua ocorrência, na prática não foi confirmada, visto que a instituição não possuía 
sistema de informações gerenciais e, como decorrência, foram verificadas falhas de comunicação externa e interna, afetando a prestação de contas junto a sociedade.

Bezerra, Borges e Valmorbida (2012) analisaram a transparência dos atos e as prestações de contas dos gastos públicos no portal da Universidade Estadual de Santa Catarina e concluíram que a instituição divulgou a maioria das demonstrações requeridas pela legislação, mas deveria aperfeiçoar o uso de notas explicativas, a fim de tornar mais clara a linguagem para o usuário do portal.

Rodrigues (2013) estudou a ocorrência de padrões de transparência ativa em sites das universidades públicas federais dos estados do sudeste e centro-oeste, observando um baixo comprometimento do ponto de vista do debate e do esclarecimento sobre a lei em seus portais.

Pereira, Machado e Carneiro (2013) analisaram a acessibilidade das IES brasileiras e propuseram um novo indicador de acessibilidade web com base em padrões nacionais e internacionais. Perceberam que as instituições públicas possuem nível de acessibilidade maior do que as instituições privadas. As regiões nordeste e sul obtiveram melhores resultados, enquanto a região sudeste obteve os piores.

Matos et al. (2015) analisaram as práticas de governança eletrônica e desempenho nas universidades federais brasileiras, por meio de indicadores de desempenho das IES federais elaborados pelo Tribunal de Contas da União. O estudo concluiu que alguns portais não apresentam informações sobre o orçamento e sobre as contas públicas das universidades e que há um longo caminho até se atingir patamares esperados de prestação de contas e participação social perante atos de gestão pública.

Simões e Souza (2015) estudaram a transparência e o acesso à informação na Universidade Federal do Rio de Janeiro e constataram que há muita opacidade em detrimento da transparência efetiva nas ações da organização. Notaram um crescimento das informações disponibilizadas, mas longe do ideal exigido pela sociedade em um contexto democrático.

Faraco (2015) estudou a transparência das informações públicas nos portais das Instituições Federais de Educação Profissional da região sul do Brasil. Os resultados apontam um índice baixo de divulgação. As maiores médias ficaram para as informações gerais das instituições, como informações sobre a estrutura administrativa. As menores médias dizem respeito à divulgação de informações sobre responsabilidade social, ambiental e econômica. $\mathrm{O}$ autor constatou que nenhuma instituição cumpre integralmente as exigências da LAI. 
Gama e Rodrigues (2016) verificaram a demanda de informações contábeis em cinquenta e nove universidades públicas federais após a publicação da LAI. Cerca de 60 \% destas instituições apresentaram demanda por informações contábeis e que apesar dos esforços do governo federal em tornar públicos os dados em seus portais, este percentual se manteve praticamente sem alterações nos dois primeiros anos de publicação da Lei.

Muitos dos estudos aqui apresentados investigaram a repercussão que a legislação trouxe na disponibilização dos atos e contas públicas nas instituições investigadas, bem como a necessidade de aprimoramento da disponibilização das informações até se chegar a um patamar esperado de contas públicas.

\section{METODOLOGIA DA PESQUISA}

\subsection{ENQUADRAMENTO METODOLÓGICO}

Caracteriza-se a pesquisa, quanto aos objetivos, como descritiva, pois apresenta características de determinada amostra, por meio do estudo de múltiplos casos, com o auxílio do modelo de análise desenvolvido por Biderman e Puttomatti (2014). Assim, objetiva-se descrever as principais ocorrências positivas e negativas encontradas nos portais analisados.

Quanto à abordagem do problema, a pesquisa enquadra-se como quali-quantitativa, visto que além de quantificar questões por meio de parâmetros e indicadores, sua estruturação se deu a partir da observação de critérios legais para a obtenção do nível de transparência das instituições de ensino analisadas (RICHARDSON, 1999). Assim, é quantitativa por conta do uso de métricas que permitirão o ranqueamento destas instituições e é qualitativa, pois visa apontar a interação de variáveis, por meio da análise dos dados primários coletados.

Quanto ao procedimento de pesquisa, por envolver a investigação do fenômeno em mais de uma organização, configura-se como um estudo de múltiplos casos, abarcando vinte e nove instituições. Sobre os procedimentos técnicos, a coleta de dados foi realizada por observação direta dos portais das instituições, com apoio do modelo de Biderman e Puttomatti (2014) e também por meio da análise documental, com fontes constituídas por documentos que, em sua maioria, não sofreram tratamentos analíticos (GIL, 1999). Quanto aos resultados, a pesquisa é aplicada, visto que busca resolver problemas concretos. 


\subsection{PROCEDIMENTOS PARA COLETA DE DADOS}

Optou-se pelo método de análise desenvolvido por Biderman e Puttomatti (2014) para a Organização Não Governamental - Contas Abertas, que permite a atribuição de notas, informando o nível de transparência das contas públicas de instituições em diferentes esferas. O índice encontra-se na sua terceira edição e foi revisado por uma equipe de especialistas em finanças e contas públicas, fornecendo credibilidade pela opção da metodologia. A elaboração do índice se deu com base na Lei Complementar $n^{\circ} 131$ (2009), regulamentada pelo Decreto $\mathrm{n}^{\circ} 7.185$ (2010) e na Lei $\mathrm{n}^{\circ} 12.527$ (2011), regulamentada pelo Decreto $\mathrm{n}^{\circ} 7.724$ (2012).

Sob o ponto de vista dos critérios estabelecidos por esta metodologia são considerados transparentes quanto às contas públicas aquelas entidades ou órgãos que possuem sites que atendam aos parâmetros: a) Conteúdo; b) Série Histórica e Frequência de Atualização e c) Usabilidade (BIDERMAN; PUTTOMATTI, 2014).

\subsection{AMOSTRA}

A região sul do Brasil foi escolhida como escopo da pesquisa por ser uma das regiões com maior percentual de pessoas vinculadas ao ensino superior (IBGE, 2015). Optou-se por selecionar os portais eletrônicos dos institutos federais de educação e das universidades federais, estaduais e municipais desta região para comporem o universo da pesquisa.

Quadro 1 Caracterização da amostra da pesquisa

\begin{tabular}{|c|c|c|c|c|}
\hline Estado & Instituições Federais & Instituições Estaduais & $\begin{array}{c}\text { Instituições } \\
\text { Municipais }\end{array}$ & Institutos Federais \\
\hline PR & $\begin{array}{c}\text { UNILA; UFPR; } \\
\text { UFTPR } \\
\text { UNELP UEM; } \\
\text { UNICENTRO; UENP; } \\
\text { UNIOESTE }\end{array}$ & UNIUV & IFPR \\
\hline RS & $\begin{array}{c}\text { UFCSPA; UFPEL; } \\
\text { UFS; UNIPAMPA; } \\
\text { FURG; UFRGS }\end{array}$ & UERGS & IFSC; IFC \\
\hline SC & UFSC & UDESC & USJ; FMP & $\begin{array}{c}\text { IFRS; IFSUL; } \\
\text { IFFARROUPILHA }\end{array}$ \\
\hline PR/RS/SC & UFFS & - & - & - \\
\hline
\end{tabular}

Fonte: elaborado pelos autores.

Foram selecionadas vinte e nove instituições por meio do Portal Eletrônico do Ministério da Educação instituições, sendo onze universidades federais, nove universidades estaduais, três universidades municipais e seis institutos federais de educação, dispostas no 
Quadro 1. A pesquisa ocorreu entre os meses de setembro e outubro de 2017, demonstrando um retrato momentâneo.

\section{RESULTADOS DA PESQUISA}

\subsection{ANÁLISE QUANTO AO PARÂMETRO CONTEÚDO}

O parâmetro conteúdo engloba a disponibilização de todas as fases da execução orçamentária, detalhamento da arrecadação, acesso fácil às diversas classificações orçamentárias e ampla divulgação de processos licitatórios, convênios, informações sobre os servidores públicos, contratos de repasses, termos de parceria e o patrimônio da entidade. São onze indicadores específicos para este parâmetro. A pontuação máxima a ser obtida é de 2750 pontos, correspondendo a $55 \%$ do total do índice (Biderman \& Puttomatti, 2014).

Os resultados apontam a UNILA e a UFSM com maior pontuação para o parâmetro, com índices de 75,65\% e 75,27\%, respectivamente, resultado da correta remissão ao conteúdo armazenado nos portais governamentais, bem como pela produção e disponibilização de conteúdos próprios. Apenas sete instituições atingiram 50\% ou mais para o parâmetro, sendo seis delas instituições federais e uma delas vinculada ao Estado do Paraná.

Dos vinte e nove portais analisados, três não apresentam quaisquer informações referentes ao parâmetro conteúdo, são eles: USJ, FMP e UERGS. Os indicadores mais omitidos pelas instituições são os restos a pagar pagos e os restos a pagar, que são as despesas empenhadas, mas não pagas até o dia 31 de dezembro, impossibilitando que o usuário tenha uma ampla visão sobre o equilíbrio orçamentário da instituição.

Dentre as IES municipais, somente a UNIUV pontuou, pois apresenta em seu portal a opção de acesso às licitações, sem necessidade de cadastro. Nenhuma instituição municipal apresentou quaisquer dados referentes à execução e a classificação orçamentária, documento de empenho e pagamento, beneficiários de pagamento, dentre outros quesitos previstos na metodologia. No Quadro 2 são apresentadas as pontuações médias por grupo de instituições.

Quadro 2 Notas do parâmetro conteúdo por grupos de instituições.

\begin{tabular}{|c|c|c|}
\hline Grupos de Instituições & Pontuação Média & \% Médio \\
\hline Universidades Federais & 1167,27 pontos & 42,44 \\
\hline Universidades Estaduais & 938,75 pontos & 34,13 \\
\hline Universidades Municipais & 50 pontos & 1,81 \\
\hline Institutos Federais & 943,33 pontos & 34,30 \\
\hline
\end{tabular}

Fonte: elaborado pelos autores. 


\section{PRÁTICAS DE ACCOUNTABILITY: TRANSPARÊNCIA E PRESTAÇÃO DE CONTAS NAS INSTITUIÇÕES PÚBLICAS DE ENSINO SUPERIOR DA REGIÃO SUL DO BRASIL \\ DOI: http://dx.doi.org/10.5007/1983-4535.2020v13n3p98}

Uma análise complementar foi feita em cada instituição, a partir das informações de portais governamentais, sobre os quesitos classificação (funcional programática e natureza da despesa), detalhamento de pessoal, fonte de recursos, documento de empenho e documento de pagamento, constatando-se a existência de assimetria informacional entre as informações dos portais de cada instituição e os portais governamentais.

Se um dos objetivos do governo eletrônico é combater a assimetria informacional existente entre o governo e a sociedade, diminuindo os problemas de agência que existem entre os gestores públicos e os cidadãos (G2C) (MELLO, 2009), o resultado da pesquisa indica que há uma assimetria informacional também na relação Governo para Governo (G2G), que se diminuída pelas entidades analisadas resultará em níveis melhores de transparência. Nesse sentido, as instituições poderiam disponibilizar em suas páginas, links de redirecionamento aos portais governamentais e correlatos, concomitante a instruções de acesso ao internauta, indicando o conteúdo a ser obtido, para que estes possam acessar as informações que desejam.

\subsection{SÉRIE HISTÓRICA DISPONÍVEL E FREQUÊNCIA DE ATUALIZAÇÃO}

Este parâmetro envolve a disponibilização de séries histórias (entre quatro e dez anos ou mais) que devem ser atualizadas de forma sistêmica (diária, semanal, quinzenal, etc.), permitindo que seja realizado o entrelaçamento de informações. Ao todo são dois indicadores para este parâmetro. A pontuação máxima a ser obtida é de 250 pontos e representa $5 \%$ do total (BIDERMAN; PUTTOMATTI, 2014).

Nove instituições atingiram a nota máxima para a série histórica e sete para a frequência de atualização. Três instituições atingiram notas máximas para ambos os quesitos: UEM, UFCSPA e UFSM. Ao todo, oito instituições deixaram de apresentar ao menos quatro anos de série histórica das suas contas públicas, fato que conjugado com uma frequência de atualização superior a sessenta dias rendeu-lhes pontuação zero para o parâmetro.

No que tange à frequência de atualização, onze instituições atualizam informações sobre a despesa de suas contas em um prazo superior a sessenta e um dias. Outras onze o fazem num prazo entre trinta e um a sessenta dias e somente sete instituições atendem a liberação das informações em tempo real. O reduzido número de instituições que atinge a nota máxima serve de alerta quanto ao não cumprimento da legislação que estabelece a divulgação 
das informações financeiras e orçamentárias em tempo real, conforme disposto no inc. II, do $\S$ $2^{\circ}$ do Art. $2^{\circ}$ do Decreto $n^{\circ} 7.185$ (2010).

Quadro 3 Notas do parâmetro série histórica e frequência de atualização por grupos de instituições

\begin{tabular}{|c|c|c|}
\hline Grupos de Instituições & Pontuação Média & \% Médio \\
\hline Universidades Federais & 125,45 pontos & 50,28 \\
\hline Universidades Estaduais & 86,66 pontos & 34,67 \\
\hline Universidades Municipais & 0 pontos & 0,00 \\
\hline Institutos Federais & 100 pontos & 40,00 \\
\hline
\end{tabular}

Fonte: Elaborado pelos autores.

Quanto à série histórica, dez instituições apresentam informações sobre suas contas com dez anos ou mais. Outras dez disponibilizam informações sobre as contas entre cinco e nove anos, e nove instituições não disponibilizam acesso para anos anteriores, impedindo que o usuário faça uma análise comparativa mais aprofundada com relação às contas públicas, prejudicando diretamente a utilidade para decisões (PLATT et al, 2007).

\subsection{ANÁLISE QUANTO À USABILIDADE}

A usabilidade é o segundo parâmetro com maior relevância na metodologia utilizada, com pontuação máxima de dois mil pontos ( $40 \%$ da pontuação total). A usabilidade abarca a possibilidade de download de dados com a finalidade de se realizar tratamentos específicos e comparações estatísticas, interação com o usuário, uso de gráficos e facilidade de navegação. São cinco indicadores para este parâmetro. (BIDERMAN; PUTTOMATTI, 2014).

O primeiro quesito contempla a interação do usuário, onde são avaliados: manual de navegação, perguntas frequentes, glossário simples e interativo, fale conosco por e-mail e telefone. Nenhuma instituição obteve pontuação plena para o quesito, fato que aponta para a dificuldade em se tornar mais interativas as suas informações, criando obstáculos ao acesso à informação de forma transparente, objetiva e com linguagem de compreensão facilitada.

Não foram encontrados os glossários interativo ou simples. Poderiam utilizar páginas de redirecionamento a glossários já utilizados pela administração pública, já que os termos técnicos são os mesmos. Outro aspecto desabonador é a ausência de manual de navegação, à exceção da UFSM, que inova, em relação aos dados que apresenta, pois indica os melhores caminhos para navegação em busca das informações relativas às contas públicas da instituição, facilitando ao usuário obter os dados desejados, seja na página da entidade ou em páginas auxiliares de pesquisa. Um aspecto positivo é que todas possuem canal de fale 
conosco, indicando telefone e e-mail para contato e vinte e três $(79,31 \%)$ instituições apresentam opção para acesso de perguntas frequentes.

Quanto à possibilidade de download, nenhuma atendeu ao quesito de forma plena ou limitada. O que se permite é baixar fragmentos de dados, como licitações e contratos específicos ou planilhas já elaboradas com informações agregadas sobre conteúdo já elaborado. Há certos mecanismos de busca que trazem resultados que sequer permitem ao usuário fazer o download do conteúdo. Um aspecto a ser salientado é que as instituições trabalham com dados em formato .pdf, não possibilitando o download de suas contas públicas em formato de dados abertos, os quais podem ter utilidade para a atuação de vários grupos de indivíduos e organizações, por trazer benefícios em áreas como transparência e controle democrático, participação popular e empoderamento dos cidadãos (DIETRICH et al, 2011).

Destaca-se que iniciativas para disponibilizar dados abertos já começaram a ser aplicadas por parte destas instituições, como o IFC, UFRGS e UNIPAMPA. Esta última disponibiliza alguns conteúdos para download, tais quais: informações sobre docentes, técnicos administrativos, acadêmicos e frota de veículos. No entanto, nenhuma destas apresenta banco de dados sobre suas contas públicas.

Quanto à delimitação temporal das consultas, apenas a UEPG e a UNICENTRO permitem delimitação temporal das consultas de forma plena, tendo em vista que se pode relacionar a pesquisa por data de início e fim, possibilitando a emissão de resultados mensais, bimestrais, trimestrais, semestrais e anuais. Outras dezenove $(65,51 \%)$ instituições permitem aferição dos seus dados por delimitações temporais limitadas, com maior predominância para a delimitação mensal, encontrada em onze destas instituições.

Sobre a facilidade de navegação, o primeiro item diz respeito à forma com que as instituições disponibilizam o conteúdo sobre as contas públicas, se concentrada em um único site ou linkado e nominado na página principal. Os resultados apontam que nenhuma instituição mantém os dados sobre suas contas de forma concentrada em único site, sendo que vinte e cinco instituições $(86,20 \%)$ se utilizam de link na página principal que dará acesso às contas púbicas da instituição, em atendimento ao artigo $7^{\circ}$ do Decreto $n^{\circ} 7.724$ (2012).

Outro aspecto a salientar é que embora não haja exigência legal, o fato de as instituições não utilizarem um padrão de nomenclatura para as referidas seções de divulgação das informações foi considerado um aspecto desabonador, pois dificulta a localização de forma célere destas seções, inibindo um amplo acesso a elas e a sua divulgação. 


\section{PRÁTICAS DE ACCOUNTABILITY: TRANSPARÊNCIA E PRESTAÇÃO DE CONTAS NAS INSTITUIÇÕES PÚBLICAS DE ENSINO SUPERIOR DA REGIÃO SUL DO BRASIL \\ DOI: http://dx.doi.org/10.5007/1983-4535.2020v13n3p98}

Neste sentido, foram encontrados diversos títulos para nomear as seções, como: Transparência, Acesso à Informação, Portal de Transparência e Prestação de Contas. Salientase que o banner na página inicial não foi encontrado em dezesseis $(55,17 \%)$ dos vinte e nove sítios eletrônicos analisados, os quais se utilizam de formas distintas para remeter o usuário às suas seções sobre as contas públicas, em contraponto ao que prevê a Secretaria de Comunicação Social da Presidência da República, ao indicar que o acesso se dê pelo endereço "www.domíniodoórgão/acesso-a-informacao". O que se observa, no entanto, é a utilização de distintos endereços para acesso à seção, com atendimento de apenas cinco instituições ao padrão ideal: UNILA, UFSM, IFPR, UFTPR e IFC.

Outro item relevante para a facilidade de navegação é a disponibilização do conteúdo sobre as contas públicas em formato html. Neste sentido, quatorze $(48,27 \%)$ instituições atenderam ao padrão tido como ideal, mas a maioria $(51,73 \%)$ não disponibilizava formulários para consulta. Isso acarreta aos usuários um menor nível de interação, já que muitas vezes as informações são disponibilizadas em planilhas pré-formatadas, relegando-os a uma condição passiva na obtenção de informações. As quatorze instituições que ofertam esta ferramenta trazem opções restritas de pesquisa, exigência de preenchimento e campos interdependentes, impedindo a plena personalização da consulta pelo usuário. A LAI (2011) determinou que os portais governamentais possibilitem a gravação de relatórios, por meio de formulários, em diversos formatos eletrônicos, de forma a facilitar a análise das informações.

No que tange à liberdade de preenchimento de formulários, nenhuma instituição atingiu nota máxima. Outro aspecto que poderia facilitar a compreensão dos usuários quanto às contas públicas das instituições é a utilização de gráficos e auxílios visuais pelas instituições, mas esta abordagem não foi encontrada em nenhuma das instituições analisadas.

Nenhuma instituição atingiu nota superior a 50\% da usabilidade, conforme Quadro 4, indicando que há um longo caminho a ser percorrido pelas IES até que os usuários consigam encontrar e compreender os dados desejados com facilidade. A UFSM obteve a melhora avaliação para a usabilidade, com 33,54\%. O quesito com maior pontuação média entre as universidades foi a interação com o usuário, com percentual de atendimento de 58,27\%.

Quando se objetiva informar algo ao público de maneira eficaz, deve-se disponibilizar o acesso à informação e zelar pela forma com que o conteúdo é apresentado, considerando os dados, a linguagem e informações produzidas, por meio de instrumentos capazes de garantir um fluxo de comunicação contínua entre governo e sociedade (FARACO, 2015). 
Quadro 4 Notas do parâmetro usabilidade por grupos de instituições

\begin{tabular}{|c|c|c|}
\hline Grupos de Instituições & Pontuação Média & \% Médio \\
\hline Universidades Federais & 415,45 pontos & 20,27 \\
\hline Universidades Estaduais & 368,88 pontos & 18,44 \\
\hline Universidades Municipais & 133,33 pontos & 6,67 \\
\hline Institutos Federais & 456,66 pontos & 22,83 \\
\hline
\end{tabular}

Fonte: Elaborado pelos autores.

Por conta disto, todas as instituições necessitam desenvolver formas para tornar seus bancos de dados disponíveis para download, além de criarem novos formulários que permitam ao usuário o cruzamento diversificado de informações sobre classificação e execução orçamentária, além de fornecerem gráficos e auxílios visuais com o intuito de facilitar a compreensão do seu conteúdo.

\subsection{RANKING DA PESQUISA E ANÁLISE GLOBAL}

Os resultados expostos na Tabela 1 revelam que grande parte dos portais das IES do sul do Brasil não alcançou níveis satisfatórios de transparência, com atendimento parcial aos itens previstos na metodologia analisada.

Três instituições atingiram pontuação superior a 50\% do total do índice: UFSM, UNILA e IFPR. Dezoito instituições obtiveram pontuação inferior a $30 \%$ e outras oito no patamar entre 30 e $50 \%$. Considerando que doze destas instituições (UFPR, UFCSPA, UNIPAMPA, UFRGS, UFSC, UDESC, USJ, IFSC, IFC, IFRS, IFFARROUPILHA) possuem a transparência como um dos seus valores fundamentais, pode-se dizer que quanto às contas públicas este valor precisa ser aprimorado, compreendido e difundido pelas instituições analisadas, para que se configure como um modo de conduta para toda a organização.

Entre as dez instituições melhores avaliadas, sete são federais, sendo cinco universidades e dois institutos e outras três vinculam-se ao Estado do Paraná: UEPG, UNICENTRO e UEM. A seguir são apresentados os resultados individuais das instituições analisadas, em forma de ranking, elaborado a partir da pontuação total, resultando no índice de transparência de acordo com Bidermann e Puttonatti (2014). As entidades com maior pontuação para este parâmetro foram UNILA, UFSM e o IFPR, atingindo índices superiores a $70 \%$, pois combinaram a disponibilização de informações por elas custodiadas com o redirecionamento para informações disponibilizadas em outros portais governamentais. 


\section{PRÁTICAS DE ACCOUNTABILITY: TRANSPARÊNCIA E PRESTAÇÃO DE CONTAS NAS INSTITUIÇÕES PÚBLICAS DE ENSINO SUPERIOR DA REGIÃO SUL DO BRASIL \\ DOI: http://dx.doi.org/10.5007/1983-4535.2020v13n3p98}

Dentre todos os parâmetros, a usabilidade foi o que apresentou a pior avaliação. Em média, as instituições atingiram apenas 369,60 pontos dos 2.000 possíveis, indicando que há um longo caminho a percorrer até que os usuários consigam encontrar informações com facilidade e compreender seu conteúdo com o auxílio de ferramentas dos próprios portais.

Tabela 1 Classificação individual das IES analisadas

\begin{tabular}{lccccc}
\hline IES & Conteúdo & SH e Freq. & Usabilidade & Soma & \% \\
\hline UFSM & 2070 & 250 & 670 & 2990 & $59,80 \%$ \\
\hline UNILA & 2080 & 250 & 630 & 2960 & $59,20 \%$ \\
\hline IFPR & 1950 & 220 & 650 & 2820 & $53,40 \%$ \\
\hline IFSC & 1550 & 220 & 500 & 2270 & $45,40 \%$ \\
\hline UEPG & 1530 & 90 & 620 & 2240 & $44,80 \%$ \\
\hline UFCSPA & 1440 & 250 & 500 & 2190 & $43,80 \%$ \\
\hline UNICENTRO & 1270 & 240 & 620 & 2130 & $42,60 \%$ \\
\hline UFSC & 1390 & 110 & 420 & 1920 & $38,40 \%$ \\
\hline UNIPAMPA & 1110 & 100 & 450 & 1660 & $33,20 \%$ \\
\hline UEM & 790 & 250 & 530 & 1570 & $31,40 \%$ \\
\hline UENP & 1090 & 50 & 420 & 1560 & $31,20 \%$ \\
\hline UFRGS & 1110 & 110 & 250 & 1470 & $29,40 \%$ \\
\hline IFRS & 870 & 80 & 500 & 1450 & $29,00 \%$ \\
\hline UDESC & 980 & 110 & 300 & 1390 & $27,80 \%$ \\
\hline UFFS & 740 & 60 & 500 & 1300 & $26,00 \%$ \\
\hline UFPEL & 920 & 110 & 250 & 1280 & $25,60 \%$ \\
\hline UNIOESTE & 960 & 30 & 280 & 1270 & $25,40 \%$ \\
\hline IFSUL & 650 & 80 & 500 & 1230 & $24,60 \%$ \\
\hline UFPR & 910 & 60 & 250 & 1220 & $24,40 \%$ \\
\hline UEL & 900 & 10 & 300 & 1210 & $24,20 \%$ \\
\hline UFTPR & 640 & 110 & 400 & 1150 & $23,00 \%$ \\
\hline IFC & 290 & 0 & 370 & 660 & $13,20 \%$ \\
\hline FURG & 430 & 0 & 220 & 650 & $13,00 \%$ \\
\hline IFARROUPILHA & 350 & 0 & 220 & 570 & $11,40 \%$ \\
\hline UNESPAR & 150 & 0 & 100 & 250 & $5,00 \%$ \\
\hline UNIUV & 150 & 0 & 100 & 250 & $5,00 \%$ \\
\hline USJ & 0 & 0 & 200 & 200 & $4,00 \%$ \\
\hline UERGS & 0 & 0 & 120 & 120 & $2,40 \%$ \\
\hline FMP & 0 & 0 & 100 & 100 & $2,00 \%$ \\
\hline & & & &
\end{tabular}

Fonte: Elaborado pelos autores.

Os baixos níveis de usabilidade apontam que o elemento da transparência pública que exige maior adequação por parte das instituições, é a compreensibilidade (PLATT et al, 2007). A baixa usabilidade também induz à inocorrência da transparência. Não conseguindo apresentar em linguagem clara e de fácil compreensão às contas públicas, o que verdadeiramente as instituições promovem é a publicidade dos seus atos. 


\section{CONSIDERAÇÕES FINAIS}

O panorama da disponibilização das contas públicas permitiu identificar um baixo nível de transparência nas IES públicas do sul do Brasil. Verificou-se que estas instituições ainda são incapazes de dar pleno atendimento à LAI, a qual trouxe novidades importantes para a transparência pública. O descumprimento de diversos aspectos legais implica na oferta de um conteúdo desqualificado pela administração, o que tolhe de inúmeros usuários interessados a possibilidade concreta de realizarem um controle social mais efetivo.

O contexto de baixa usabilidade encontrado na pesquisa, somado ao fato de poucas instituições garantirem acesso às informações de períodos anteriores, demonstra que estas instituições estão mais próximas de promoverem a publicidade do que a transparência de suas contas e, consequentemente, a accountabiliy. Um dos motivos está na condução inadequada de práticas de gestão do conhecimento, resultando na incapacidade destas instituições explorarem e disponibilizarem de forma clara aos seus usuários as informações vinculadas a outros portais governamentais e que, muitas das vezes, foram produzidas por elas próprias.

As melhores notas foram de instituições que conseguiram efetuar este redirecionamento, apontando este como o caminho mais célere para melhoria do conteúdo disponibilizado, pois não demandaria grandes esforços técnicos e financeiros para serem incorporados e atualizados. Um exemplo de adequação é a UFSM, a qual se vale de indicações pormenorizadas para levar o usuário a ter acesso às suas contas públicas.

Há de se ressaltar, no entanto, que qualquer análise sobre a transparência ativa das instituições deverá considerar os desafios adstritos às instituições públicas, como a formação de recursos humanos especializados, infraestrutura tecnológica e tratamento prévio da informação a ser disponibilizada (RODRIGUES, 2013).

Além do conteúdo, como contribuição a estas instituições, fica a necessidade de aperfeiçoar a linguagem das informações disponibilizadas de forma a tornarem-nas mais compreensíveis aos públicos que se destinam. Os portais, como ferramentas do governo eletrônico, necessitam desenvolver iniciativas de aproximação aos seus usuários e combater a assimetria informacional existente entre governo e a sociedade (MELLO, 2009). Neste sentido, uma das barreiras para a concretização da concepção societal de accountability é a necessidade de o Estado conceder iniciativas de interação com a sociedade (VIEIRA, 2005).

Uma prática auxiliar na obtenção de níveis melhores de usabilidade e, que, consequentemente, aproxima o cidadão das contas públicas é a disponibilização de conteúdo 
no formato de dados abertos. Embora as instituições ainda não disponibilizem banco de dados abertos sobre suas contas púbicas, iniciativas como as da UFRGS, IFC e UNIPAMPA indicam um momento de transição e resultam em ferramentas que aumentem a transparência. Ainda em termos de discussão e convite a partição popular, ressalta-se o IFSC que desenvolveu informativos sobre o orçamento, explicando as consequências dos cortes governamentais nas contas públicas da instituição e os casos de orçamento participativo da UDESC e da UEM.

Em decorrência dos baixos níveis de transparência das contas públicas, recomenda-se pesquisa sobre as intervenções realizadas pelos órgãos de controle nas IES, de forma a verificar a ocorrência da accountability horizontal. Por fim, sugere-se que seja efetuada uma pesquisa sobre as solicitações de acesso à informação das contas públicas destas instituições, com base na LAI, relacionando-as com os níveis de transparência ativa apresentados nesta pesquisa e em outras similares. Como limitações dos resultados, podem ocorrer imprecisões quanto à atribuição das pontuações, uma vez que alguns quesitos contêm certa subjetividade, resultando em avaliações distintas a depender da compreensão do avaliador. Além disso, os resultados se referem à amostra selecionada para a pesquisa.

Espera-se ter contribuído para evidenciar a importância da disponibilização das contas públicas nos portais eletrônicos das IES públicas, apontando as limitações encontradas e sugestões de melhoria, de forma a propiciar maior transparência para estas instituições.

\section{REFERÊNCIAS}

ANDRADE, Rodrigo Godin de. Transparência de Câmaras Municipais dos maiores municípios brasileiros por meio de portais eletrônicos : um estudo à luz da lei de acesso à informação. Dissertação de mestrado em Administração, Universidade do Estado de Santa Catarina, SC, São Paulo, Brasil, 2014.

ARATO, Andrew. Representação, Soberania Popular e Accountability. Lua Nova, v. 55-56, p. 85-103, 2002.

BIDERMAN, Ciro; PUTTOMATTI, Giulia. Metodologia do Índice de Transparência.

BHATTA, Gambhir. Post-NPM thermes in public sector governance. State Services Commission, p. 1-16, 2003.

Constituição da República Federativa do Brasil: promulgada em 5 de outubro de 1988. Presidência da República. Casa Civil. Subchefia para Assuntos Jurídicos. 
Decreto $\mathbf{n}^{\mathbf{0}} \mathbf{7 . 7 2 4}$, de 16 de maio de 2012. Regulamenta a Lei $\mathrm{n}^{\circ} 12.527$, de 18 de novembro de 2011, que dispõe sobre o acesso a informações previsto no inciso XXXIII do caput do art. $5^{\circ}$, no inciso II do $\S 3^{\circ}$ do art. 37 e no $\S 2^{\circ}$ do art. 216 da Constituição. Diário Oficial da União, Brasília, 16 de maio de 2012.

Lei $\mathrm{n}^{\circ}$ 12.527, de 18 de novembro de 2011. Regula o acesso a informações previsto no inciso XXXIII do art. $5^{\circ}$ e dá outras providências. Diário Oficial da União, Brasília, 18 nov. 2011. CAMPOS, Ana Maria. Accountability: quando poderemos traduzi-la para o português? Revista de Administração Pública, v. 24, n. 2, p. 30-50, fev./abr, 1990.

CENEVIVA, Ricardo. Accountability: novos fatos e novos argumentos - uma revisão da literatura recente. In: Encontro de Administração Pública e Governança da Anpad, São Paulo: Anpad, 2006.

CRUZ, Flávio da. et al.. Lei de Responsabilidade Fiscal Comentada: lei complementar $\mathrm{n}^{\mathrm{o}}$ 101, de 4 de maio de 2000. Editora Atlas: São Paulo. 2011.

DIETRICH, D.; et al. Manual dos dados aberto: governo.

GAMA, J. R.; RODRIGUES, G M. Transparência e acesso à informação: um estudo da demanda por informações contábeis nas universidades federais

brasileiras. Transinformação, Campinas, v. 28, n. 1, p. 47-58, abril, 2016.

GIL, Antonio Carlos. Métodos e técnicas de pesquisa social. 5ª ed. São Paulo: Atlas, 1999.

FARACO, Bruno Pereira. Transparência das informações públicas nos portais das instituições federais de educação profissional da região Sul do Brasil. Dissertação (mestrado). Universidade Tecnológica Federal, 2015.

INSTITUTO BRASILEIRO DE GEOGRAFIA E ESTATÍSTICA - IBGE. Pesquisa Nacional por Amostra de Domicílios - PNAD, 2015.

INTOSAI -International Organization of Supreme Audit Institutions Auditing Standards Basic Principles in Government Auditing. (ISSAI 100). Viena, 2010.

JARDIM, J.M. Transparência e opacidade do Estado no Brasil: usos e desusos da informação governamental. Niterói: Editora UFF, 1999.

Lei Complementar n. ${ }^{\circ}$ 101, de 4 de maio de 2000 (Lei de Responsabilidade

Fiscal). Estabelece normas de finanças públicas voltadas para a responsabilidade na gestão fiscal e dá outras providências. Diário Oficial da União, Brasília, 5 maio, 2000.

Lei Complementar n. ${ }^{0}$ 131, de 27 de maio de 2009. Acrescenta dispositivos à Lei Complementar no 101, de 4 de maio de 2000. Diário Oficial da União, Brasília, 28 maio, 2009. 
Decreto $\mathbf{n}^{\circ}$ 7.185, de 27 de maio de 2010. Dispõe sobre o padrão mínimo de qualidade do sistema integrado de administração financeira e controle, no âmbito de cada ente da Federação. Diário Oficial da União, Brasília, 27 maio, 2010.

LEITE FILHO, G. A.; COLARES, A. F. V.; ANDRADE, I. C. F. Transparência da Gestão Fiscal Pública: um estudo a partir dos portais eletrônicos dos maiores munícipios do Estado de Minas Gerais. Revista Contabilidade Vista \& Revista, ISSN 0103-734X, Universidade Federal de Minas Gerais, Belo Horizonte, v. 26, n. 2, p. 114-136, maio/ago, 2015.

LOPES, Cristiano Aguiar. O uso das Tecnologias da Informação e Comunicações nas políticas de acesso à informação pública na América Latina. Anais do I Circuito de Debates Acadêmicos, 2011.

LYRIO, Maurício Vasconcellos Leão et al. Proposta de um modelo para avaliar o grau de transparência das demonstrações financeiras publicadas por uma instituição pública de ensino superior brasileira: a abordagem da metodologia multicritério de apoio à decisão construtivista: contabilidade, gestão e governança. Revista UnB Contábil, v.11, n.1-2, p.170$186,2008$.

MARIA, João Francisco Araújo. Desenho institucional e accountability: pressupostos normativos da teoria minimalista. Revista de Sociologia Política, Curitiba, v. 18, n. 35, fev. 2010 .

MATOS, N. B. et al.. Práticas da governança eletrônica e desempenho: uma análise das universidades federais brasileiras. Registro Contábil - RECONT. UFAL - Maceio/AL, Vol. $6, \mathrm{n} 2,2015$.

MELLO, G. R. Estudo das práticas de governança eletrônica: instrumento de controladoria para a tomada de decisões na gestão dos estados brasileiros. 2009. Tese de Doutorado. Programa de Pós-Graduação em Curso de Ciências Contábeis. Universidade de São Paulo, São Paulo-SP, 2009.

MIGUEL, Luis Felipe. Impasses da accountability: dilemas e alternativas da representação política. Revista de Sociologia Política, Curitiba, n. 25, p. 25-38, nov. 2005.

MUlGan, R. Accountability: an ever-expanding concept? Public Administration, 78, 3, 555-573, 2000.

PEREIRA, A.S.; MACHADO, A.M.; CARNEIRO, T.C. Avaliação da acessibilidade dos sítios eletrônicos das instituições de ensino superior brasileiras. Informação \& Sociedade, v.23, n.3, p.123-142, 2013. 